Indexed by

\title{
Scopus
}

\section{PERFORMANCE ANALYSIS OF WATERJET PROPULSION ON AN UNMANNED SURFACE VEHICLE MODEL}

Muhammad Arif Budiyanto

Universitas Indonesia, Kampus

Baru UI Depok, Department of

Mechanical Engineering, Jawa

Barat, Indonesia

\section{Hamnah Ayuningtyas}

Universitas Indonesia, Kampus Baru UI Depok, Department of Mechanical Engineering, Jawa Barat, Indonesia

Key words: waterjet, inlet passage, thrust, inlet velocity ratio, efficiency doi:10.5937/jaes0-29942

Cite article:

Budiyanto Arif M., Ayuningtyas H. (2021) PERFORMANCE ANALYSIS OF WATERJET PROPULSION ON AN UNMANNED SURFACE VEHICLE MODEL, Journal of Applied Engineering Science, 19(4), 886 - 895, DOI:10.5937/ jaes0-29942 


\title{
PERFORMANCE ANALYSIS OF WATERJET PROPULSION ON AN UNMANNED SURFACE VEHICLE MODEL
}

\author{
Muhammad Arif Budiyanto*, Hamnah Ayuningtyas \\ Universitas Indonesia, Kampus Baru UI Depok, Department of Mechanical Engineering, Jawa Barat, Indonesia
}

Waterjet propulsion on an unmanned surface vehicle is a propulsion system with the working principle of taking water from the bottom of the hull into a turbine to be blown out the back, converted into the ship's thrust. The resulting thrust depends on the available water forces. The water spray in the nozzle is generated from an inlet at the bottom of the ship, which is assisted by a pump on the waterjet. In the inlet section, this will affect the distribution of flow that passes through the pump and out through the nozzle. The purpose of this study was to analyze the inlet passage of the jet of water, which is variable, with the inlet velocity ratio (IVR) to determine the maximum efficiency value of the waterjet propulsion system. The work of this study used the computational fluid dynamics (CFD) method and analytical calculations. The inlet velocity ratio was varied with values of $0.54,0.59,0.67,0.78,0.94,1.18,1.64$, and 2.38. The results of the analysis included the volume that exited the waterjet outlet and the thrust value under different conditions. The highest thrust value obtained was based on an IVR value of 2.38, which also had the maximum efficiency value of $98 \%$.

Key words: waterjet, inlet passage, thrust, inlet velocity ratio, efficiency

\section{INTRODUCTION}

A ship's propulsion system is one of the factors that has a significant effect on the operational movement of a ship. In line with the development of machinery technology, ship propulsion systems are becoming increasingly more diverse. Of course, each ship requires a specific propulsion system according to its type and the use of the ship. Waterjet propulsion is one of the systems that is growing in use for fast boats [1]. Currently, waterjet propulsion technology has been used extensively in civil and military applications because it has a high performance rating, anti-cavitation capability, reliable operation, and low noise [2]. A waterjet propulsion system can be placed in the hull of the ship, that is, at the bottom, to reduce resistance from additional parts outside the hull [3]. A waterjet propulsion system consists of an inlet tube, a waterjet pump, a nozzle, and a steering mechanism. In the system, the waterjet pump is the key tool used to create a jet of water at the exit of the nozzle with up to $90 \%$ hydraulic efficiency using advanced, modern construction methods [4].

In the last decade, several studies have been carried out to research the flow dynamics of the inlet and to investigate the effect of non-uniform suction flow on waterjet pumps [5]. Research with wind tunnel experiments found that the cross-section of the stream tube was approximately semi-elliptical in shape, resulting in a roof separation zone that was dependent on the Reynolds number [6]. Experimental analysis has studied the hydrodynamic force induced by a non-uniform suction flow in a mixed flow waterjet pump using a dynamometer; the calculation results show that the non-uniform inflow does not affect pump operation but can reduce the pump head [7]. In addition, non-uniform inflows can also lead to early cav- itation, air absorption, and weak blade and shaft loads, resulting in unnecessary noise and vibration problems [8]. Differences in output between uniform and non-uniform suction flow were also observed; the researchers noted that a large, non-uniform suction flow would result in a significant reduction in the pump head with the main feature of a distinct vortex distortion at the top, forming a circular eddy [9]. Due to flow divergence and non-uniformity, up to $9 \%$ of total power is lost at the inlet [10]. Furthermore, the interaction between the ship and the waterjet propulsion system reduces propulsion efficiency by $20 \%$ or more, and this interaction happens mostly near the inlet [11].

The International Towing Tank Conference (ITTC) Waterjets Specialist Committee has suggested research procedures for the investigation of the interaction of waterjet experimentation [12,13]. The U.S. Office of Naval Research used a pair of waterjet systems to conduct a detailed sequence of measurements on a half hull [14]. Their data scaling method took into account the disparity in the thickness of the boundary layer caused by the scale transition. As a result, even if the decreased thrust fraction in the medium velocity range was positive at the model size, this correction yielded a negative thrust reduction fraction [15]. For medium-speed wave catamarans, an experimental comparison of powering by waterjet system and screw propeller was conducted. The researchers estimated that the thrust reduction fraction for a waterjet-driven hull would be very poor [16]. The investigation of the jet of water using the integration of the electrical propulsion system on board an autonomous boat demonstrated a promising and easy technique for the efficient control of DC propulsion systems [17]. Another experimental study examined the relationship between the jet of water and the hull using 
model-scale and full-scale tests; the findings revealed potential factors leading to an overall interaction effect and identified the momentum of the jet of water caused by the lift and the moment at the center of gravity [18].

In recent decades, technology development for waterjet propulsion has continued to expand. Some researchers using computational fluid dynamic (CFD) methods simulate a waterjet propulsion system to investigate the interaction between the waterjet propeller and the hull as part of the overall design of the waterjet propulsion system $[19,20]$. Many studies have conducted simulations in order to look at the hydraulic performance of mixed flow and centrifugal pumps [21,22]. Research related to the performance effect of the waterjet pump has shown that the slower the rotational speed, the smaller the thrust provided by the propulsion pump [23]. Another study performed a numerical analysis of the interactions generated from the hull of the ship using a four-waterjet system; it found that the resulting thrust on the inner jet was greater than on the outer jet [24]. Other studies found that the resistance generated by a waterjet system with the hull was reduced as a result of a negative thrust deduction or the effect of increased drag [25]. In optimizing the inflow into the impeller, research on the optimization of the ducting design on the waterjet system has been carried out with a flush-type intake duct; the result was that the distribution of flow at the bottom of the elbow was determined to be an important source of hydraulic losses [26]. A previous simulation review of waterjet propulsion found that the performance of a convergent nozzle is higher than that of a combination nozzle, with various values ranging from $8 \%$ to $12 \%$ [27]. High-pressure waterjet propulsion analysis with a pressure vector control system used on underwater vessels has provided an overview of a system with controls that can effectively suppress overshoot and has shown better stability [28]. Another numerical study on the unsteady hydrodynamic performance of the waterjet impeller found that when the speed increases, the waterjet pump efficiency will decrease by $0.25 \%$ [29]. Previous research has also been carried out in simulations and experiments related to hydrodynamic performance with the use of foil $[30,31]$. Some waterjet propulsion studies using other CFD simulation methods include an analysis of the hydraulic characteristics of the nozzle [32], analysis of cavitation occurring in the pump [33], and hydraulic characteristics and measurement of the rotating stall suppression on a waterjet propulsion system [34]. The latest research related to waterjet propulsion has studied the hydraulic characteristics of the inlet section of the waterjet propulsion system with different flow parameters and geometries; the result was that a tilt angle with a certain range in the inlet section will improve hydraulic performance [35].

The current research involves several recent empirical studies on waterjet propulsion that have been carried out, mostly using the CFD simulation method, that have led to their hydraulic optimization. To perform the hydraulic optimization of the waterjet inlet passage, two important flow parameters were examined, namely, the inlet velocity ratio
(IVR) and ship speed, and their effect on hydraulic performance was analyzed. The purpose of this research was to obtain the thrust value generated from the installation of the waterjet system and to analyze the appropriate inlet velocity ratio to obtain the maximum thrust efficiency value on an unmanned surface vehicle. A CFD method was used to analyze the thrust of the waterjet system, which was validated with experimental data using a model ship.

\section{RESEARCH METHODOLOGY}

This research process took place sequentially and in detail, starting with the literature review process and continuing with the collection of secondary data (regarding the dimensions of the waterjet construction, the value of the inlet velocity ratio, and the speed of the ship), the creation of the 3D model designs, the CFD simulation, validation of the data obtained, and finally, the proper presentation of the data. The research method used began with identifying and formulating the problem to be studied. The research objectives were then determined. A study of the literature deepened understanding of the theoretical basis related to the problem, including reviewing data for unmanned surface vehicles. Other required data included the technical aspects of using a waterjet propulsion system. The validity and reliability of data is always a concern; tests were performed on the obtained data through the CFD-based simulation program. Data processing involved the identification of related problems. A technical analysis was created of the waterjet propulsion system, which included the conclusions and suggestions for further work.

\section{Unmanned surface vehicle models}

In this research, waterjet propulsion was used on an unmanned surface vehicle. The main dimensions of the ship model and the configuration of the control systems are shown in Table 1 and Fig. 1. This unmanned surface vehicle model used a monohull design that had good maneuverability; in this study, the ship model was made on a $1: 1$ scale.

Table 1: Ship model of unmanned surface vehicle

\begin{tabular}{|c|c|}
\hline Parameter & Value \\
\hline LOA & $=1.5 \mathrm{~m}$ \\
\hline Breadth & $=0.33 \mathrm{~m}$ \\
\hline Depth & $=0.15 \mathrm{~m}$ \\
\hline Service Speed & $=20$ knots \\
\hline Displacement & $=137.1 \mathrm{~kg}$ \\
\hline Block Coefficient & $=0.34$ \\
\hline Battery & $\begin{array}{c}=6 \mathrm{~S} \text { LiPo Battery, 22.2V, } \\
4200 \mathrm{mAh}\end{array}$ \\
\hline Engine & $\begin{array}{c}=\text { Brushless DC Motor 3674, } \\
\text { KV2075 }\end{array}$ \\
\hline Propulsion System & $\begin{array}{c}\text { = 2-Unit Waterjet System, } \\
\text { Diameter } 50 \mathrm{~mm}\end{array}$ \\
\hline
\end{tabular}




\section{Waterjet geometry}

The waterjet propulsion was designed with pipe using an inlet diameter of $50 \mathrm{~mm}$, an inlet length of $73 \mathrm{~mm}$, a nozzle diameter of $50 \mathrm{~mm}$, and an outlet outer diameter of 70 $\mathrm{mm}$. Fig. 2 shows a three-dimensional waterjet image and a waterjet propulsion slice and image. After doing the construction design on the waterjet system, a model was created using a 3D printer. The same size (a scale of 1:1) was used, and the model material was polylactide (PLA). After the $3 \mathrm{D}$ waterjet device was printed, it was ready to be installed on the unmanned surface vehicle. After installation, tests were carried out on the use of the 3D waterjet system.

\section{Boundary conditions of waterjet propulsion}

The simulation of the waterjet prolusion was carried out in two computational domains, namely, the water body and waterjet system. To consider the effect of the boundary layer on the hull, the water body was $10 \times$ Do for the width and $8 \times$ Do for the height, where Do $=50 \mathrm{~mm}$ was the diameter of the duct. The inlet was at $25 x$ Do from the beginning of the inlet water body, and for the outlet, it was $5 x$ Do behind the inlet water body. The inlet port of the water body was used as the inlet boundary of the computational domain, and the velocity conditions at the inlet were used for the computation in the inlet domain. The vessel velocity of the inlet at the inlet was $10 \mathrm{~m} / \mathrm{s}$. The detailed simulation boundary conditions are shown in Fig. 3 .

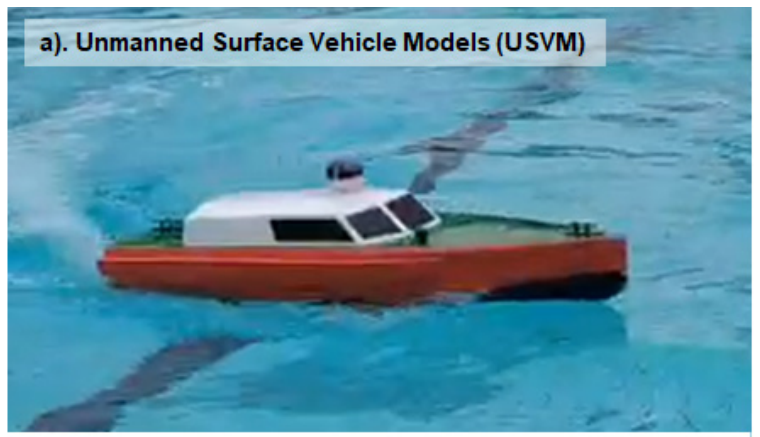

b). Part Diagram of UVSM

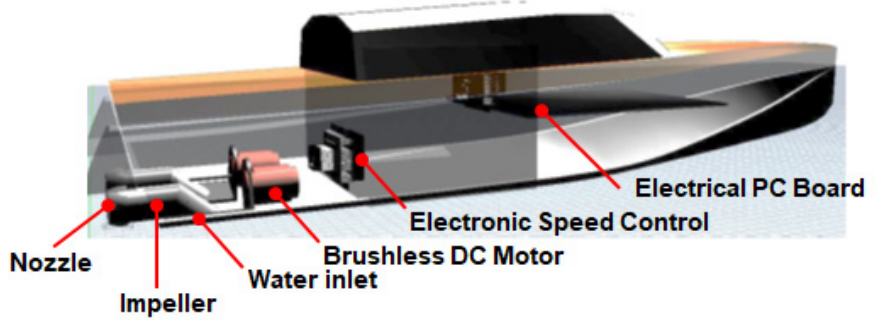

Figure 1: The ship model of the unmanned surface vehicle and remote control system
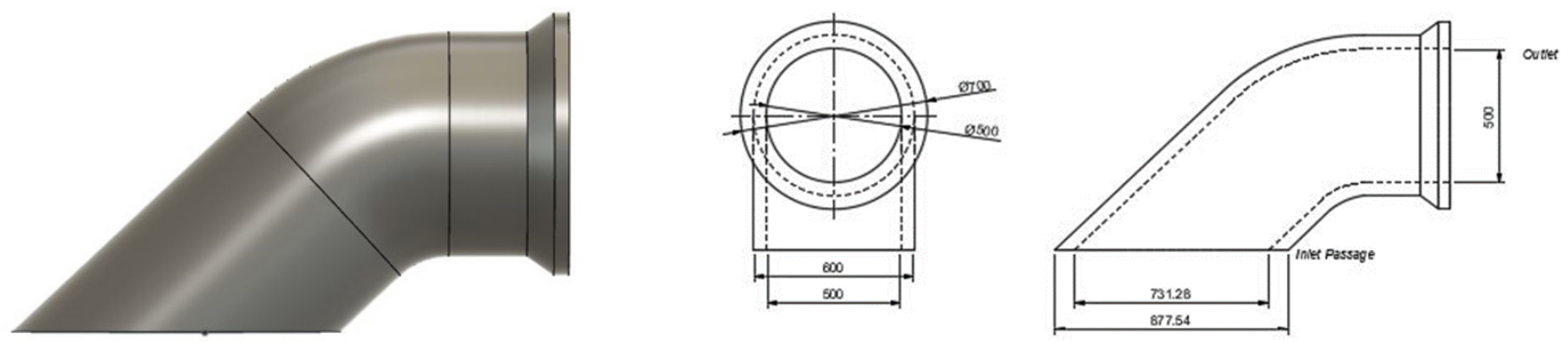

Figure 2: The geometry of the waterjet system to be used on the unmanned surface vehicle model
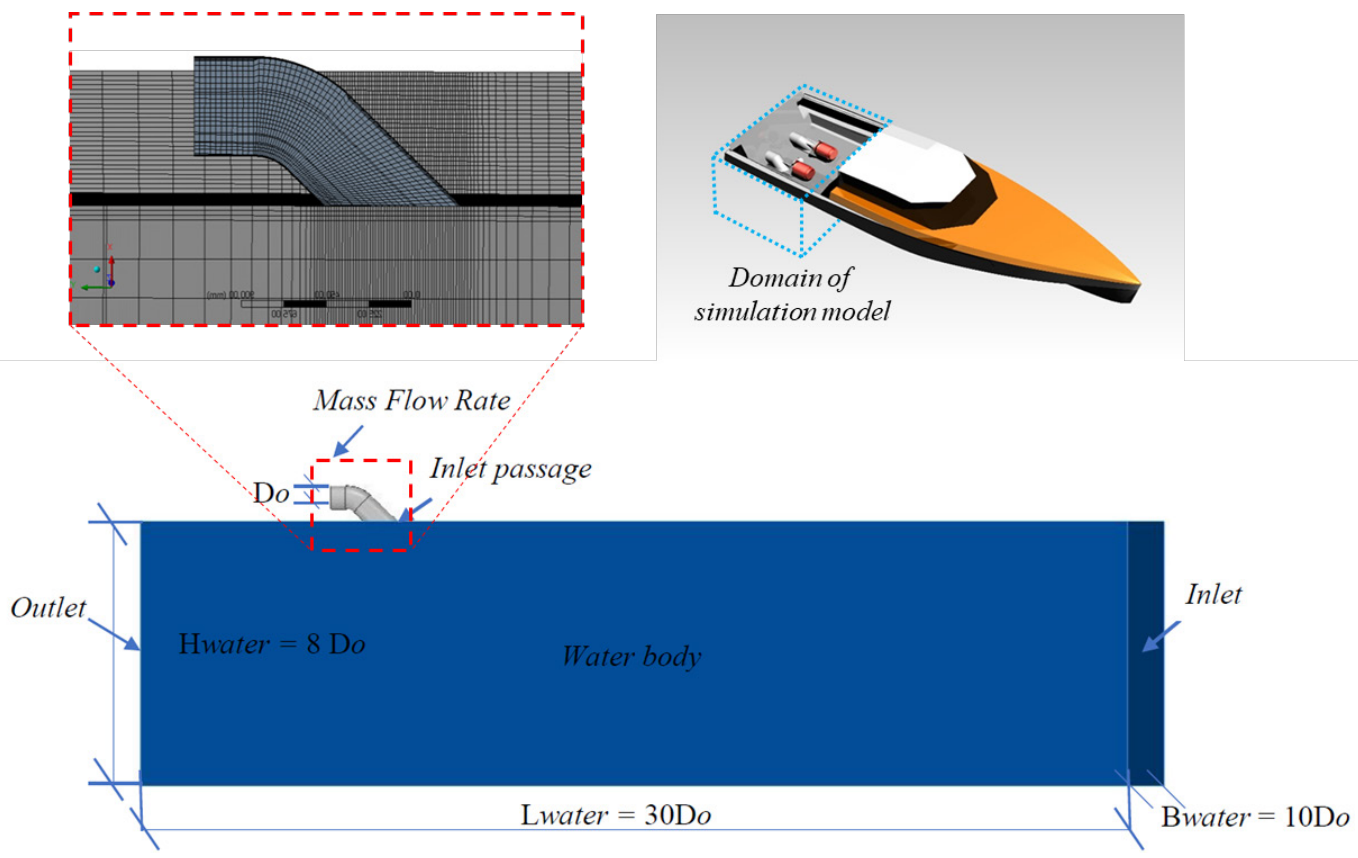

Figure 3: Dimensions and domain boundary conditions of the simulation model 
Meshing or discretization in CFD is the process of converting a continuous fluid domain into a discrete computational domain so that the fluid equations can be solved using numerical methods. In this simulation, the meshing was made to have a maximum size of $200 \mathrm{~mm}$ in the entire domain and $15 \mathrm{~mm}$ in the pipe area to obtain more detailed results there. The mesh arrangement used in this model was a hexahedral type. This type of mesh aims to obtain a higher resolution, a faster computation process, and a more efficient arrangement of the mesh volume compared to the tetrahedral type. Around the walls, mesh inflation was then used to accommodate the boundary layer phenomenon.

\section{Governing Equation and Turbulence Model}

In the model ship waterjet simulation, a single-phase flow was used with the working fluid in the water. The simulation was carried out using the well-known and reliable CFD software Ansys Fluent with an academic license [36]. The governing equations used were the Reynold's-averaged Navier-Stokes (RANS) equations, namely, the continuity equation, the momentum equation, and the energy equation shown as Equations 1, 2, and 3 , respectively [37]:

$$
\frac{D_{\rho}}{D_{t}}+\rho \frac{\partial U_{i}}{\partial x_{i}}=0
$$

$$
\begin{aligned}
& \rho \frac{\partial U_{j}}{\partial_{t}}+\rho U_{i} \frac{\partial U_{j}}{\partial x_{t}}=\frac{\partial P}{\partial x_{j}}-\frac{\partial T_{i j}}{\partial x_{i}}+\rho g_{j} \\
& \rho c_{\mu} \frac{\partial T}{\partial_{t}}+\rho c_{\mu} U_{i} \frac{\partial T}{\partial x_{i}}=-P \frac{\partial U_{i}}{\partial x_{t}}+\lambda \frac{\partial^{2} T}{\partial x_{i}^{2}}+T_{i j} \frac{\partial U_{j}}{\partial x_{i}},
\end{aligned}
$$

where the density, momentum, convection surface tension, diffusion, and mass forces are represented by the values of $\rho, U, P, \tau$, and $g$, respectively. In addition, the heat flux and heat flow from the mechanical energy are and respectively. The turbulence model equation for the domain or closure used $\mathrm{k}-\omega$ shear stress transport (SST) turbulence, which is commonly used for this scheme, as seen in Equations 4 and $5 ; \beta, \beta^{*}, \gamma, \sigma k$, and $\sigma d$ are closure constant coefficients in these equations. The Froude number, which ranges from 0.6 to 1.3 , and whether a stern foil was used were variables in this system. In the simulation, the model was at rest and the fluids flowed towards it at a steady velocity according to the different Froude numbers defined as follows:

$$
\begin{aligned}
\frac{\partial_{(\rho k)}}{\partial_{t}}+\frac{\partial_{\left(\rho u_{j} k\right)}}{\partial x_{j}}= & P-\beta^{*} \rho \omega k+\frac{\partial}{\partial x_{j}}\left[\left(\mu+\sigma_{k} \frac{\rho k}{\omega}\right) \frac{\partial k}{\partial x_{j}}\right] \\
\frac{\partial_{(\rho k)}}{\partial_{t}}+\frac{\partial_{\left(\rho u_{j} \omega\right)}}{\partial x_{j}}= & \frac{\gamma \omega}{k} P-\beta \rho \omega^{2}+\frac{\partial}{\partial x_{j}}\left[\left(\mu+\sigma_{\omega} \frac{\rho k}{\omega}\right) \frac{\partial k}{\partial x_{j}}\right]+ \\
& +\frac{\rho \sigma_{d}}{\omega} \frac{\partial k}{\partial x_{j}} \frac{\partial \omega}{\partial x_{j}}
\end{aligned}
$$

\section{Experimental Set-Up for Data Validation}

In this study, the propulsion test was carried out using the pull-test method according to the recommendations of the ITTC [38]. The test was carried out in an experimental basin with the scheme shown in Fig. 4. In this test, the tool used was a loading gauge that was linked to the model ship; the results of the load gauge development were recorded using a camera to ensure the results were accurate. The test was carried out with several variations of motor rotation, namely, $25 \%, 50 \%, 75 \%$, and $100 \%$. The results from the load gauge test were converted into a thrust value and then became validation data for the simulation results.

\section{Calculation of Inlet Velocity Ratio}

Flow velocity plays an important role in explaining the flow phenomenon at the inlet when the speed changes from ship speed to pump speed. The ITTC has identified two-dimensional coefficients, including the jet velocity ratio (JVR) and inlet velocity ratio (IVR) [38]. The IVR is a fundamental coefficient for describing the state of flow in the intake duct, and this ratio describes the velocity of flow that enters the intake throat. The calculation of ship speed, pump speed, and IVR can be calculated using Equations 1, 2, and 3, respectively:

$$
\begin{aligned}
& \text { Vship }=\frac{180}{\sqrt{\frac{D}{P}}} \\
& V_{\text {passage }}=\frac{Q}{\frac{\pi}{4} \text { Dinlet }^{2}} \\
& I V R=\frac{v_{\text {passage }}}{V_{\text {ship }}}
\end{aligned}
$$
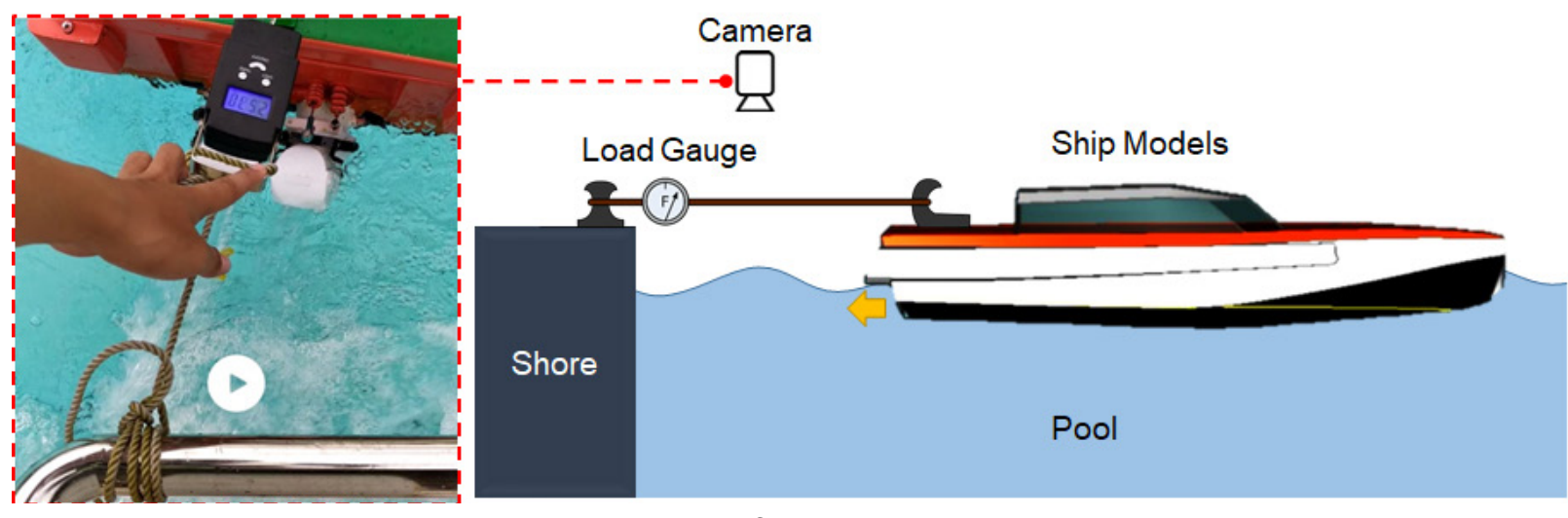

Figure 4: Waterjet performances pull test scheme 
where the notation $D$ is the load during operation or displacement, $P$ is the total power, $Q$ is the volume of flow that passes through the pump, and $D_{\text {inlet }}$ is the diameter of the suction section of the pump.

\section{Calculation of Thrust and Efficiency}

The waterjet works by sucking water from an inlet pipe located at the bottom of the ship and releasing it at high speed in the direction opposite the suction. With the increase in momentum, thrust will be generated. To determine the performance of the waterjet propulsion, the value of the thrust and efficiency as performance indicators was determined using Equations 4 and 5 [35]:

$$
\begin{aligned}
& T=\rho x Q x\left(V_{i}-V_{j}\right) \\
& \eta=\frac{\rho \cdot Q\left(V_{j}-V_{i}\right) V_{i}}{\rho \cdot Q\left(V_{j}-V_{i}\right) V_{i}+\frac{1}{2} \rho \cdot Q\left(V_{j}-V_{i}\right)^{2}},
\end{aligned}
$$

where $T$ is the thrust $(\mathrm{kN}), \rho$ is the density of the seawater $\left(\mathrm{kg} / \mathrm{m}^{3}\right), Q$ is the water flow from the pump $\left(\mathrm{m}^{3} / \mathrm{s}\right), V_{i}$ is the velocity of the water flow in the pipe $(\mathrm{m} / \mathrm{s})$, and $V_{j}$ is the speed of the ship $(\mathrm{m} / \mathrm{s})$.

\section{RESULTS AND DISCUSSION}

To analyze the performance of the waterjet inlet passage, the parameter seen is the uniformity of the axial flow in the pipe. This can be indicated from several parameters: (1) the value of the ship's waterjet thrust, (2) the distribution of the velocity in the cross-section of the pipe, (3) the pressure distribution at the cross-section of the pipe, (4) the pressure distribution and streamline side view of the pipe, (5) the graph of the axial-velocity distribution coefficient and velocity-averaged swirl angle to inlet velocity ratio, and (6) the analysis of the optimal value of the thrust.

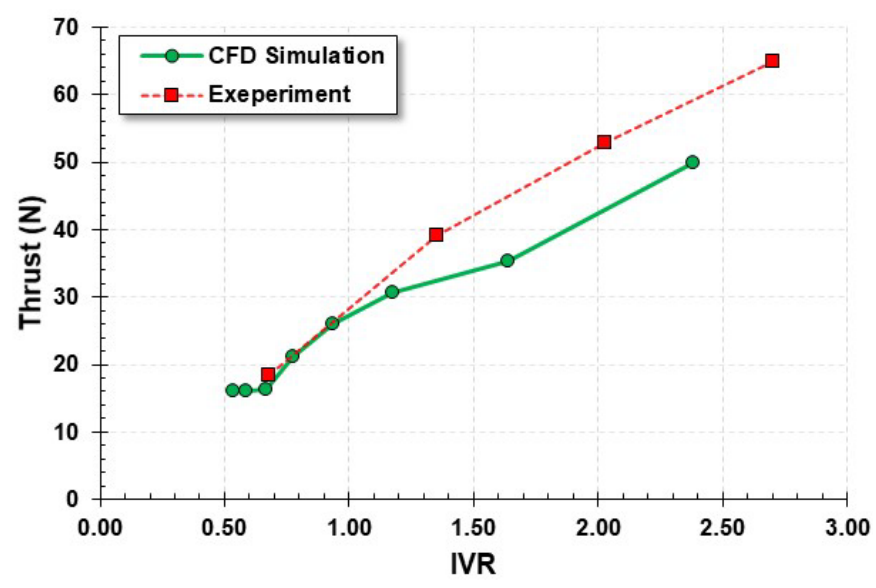

Figure 5: Effect of the inlet velocity ratio (IVR) on thrust

\section{Thrust of USV models}

During the simulation, the inlet velocity ratio varied in the value of the thrust effect. Fig. 5 shows the comparison of the thrust from the simulation results and the experimental results. The comparison of the results shows good agreement, especially in the IVR range 0.5-1.0. The effect of the IVR on the magnitude of thrust shows a linear function, where the greater the IVR, the greater the thrust value; this is consistent with previous research. At an IVR of 0.7 , the thrust value was $18 \mathrm{~N}$.

\section{Velocity Distribution in Pipe Cross-section}

In the simulation, variations were carried out, namely, changing the inlet velocity ratio. Fig. 6 shows the velocity distribution at the outlet section of the inlet with different IVR values. The variations in the IVR values were 0.59 , $0.67,0.78,0.94,1.17$, and 1.64 . These results show that the greater the value of the IVR, the higher the speed through the outlet. By increasing the IVR value, the area of the distribution of the higher speed became larger, and the area that had a lower velocity value was reduced in size.

\section{IVR 0.59}

Velocity v

Contour 1

27.24

25.43

23.61

21.79

19.98

18.16

16.35

14.53

12.71

10.90

9.08

7.26

5.45

3.63

1.82

0.00

[m s^-1]
IVR 0.67

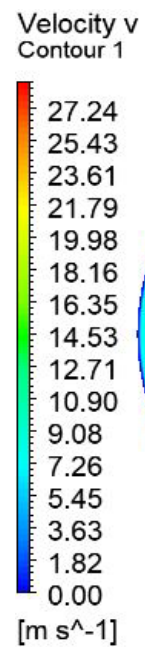

IVR 0.78

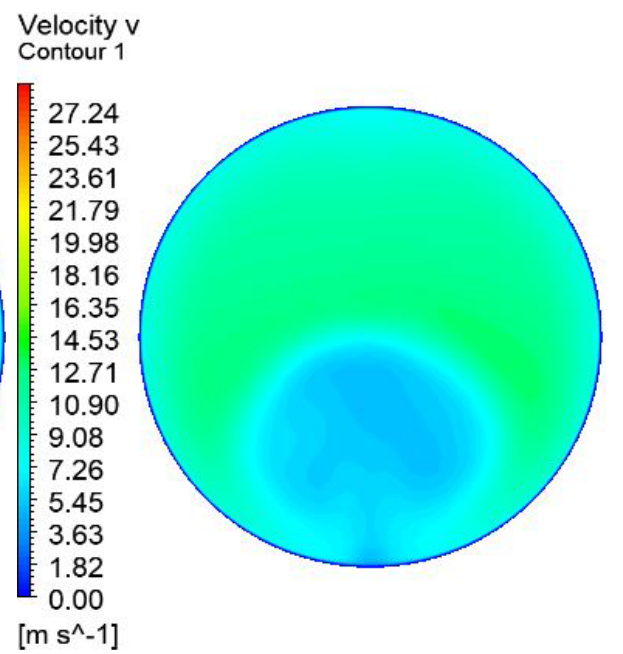




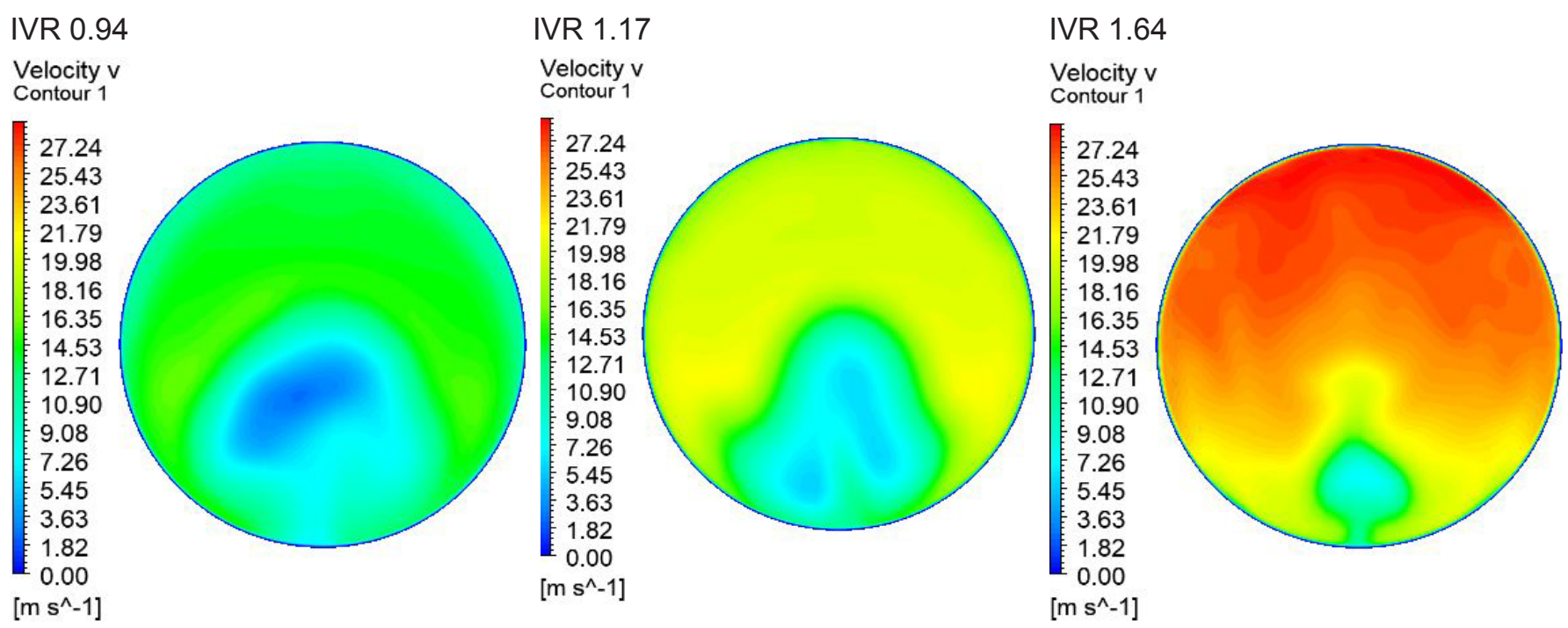

Figure 6: Effect of different IVR values at the inlet passage on axial velocity distribution at the outlet section

\section{Pressure Distribution at Pipe Cross-section}

Fig. 7 shows the results of the pressure distribution at the outlet of the inlet with different IVR values. The results show that when the IVR value was increased, the pressure at the outlet decreased continuously. The distribution area that had high pressure will change continuously to a lower pressure.

\section{IVR 0.59 \\ Pressure \\ Contour 1

$=7250.72$
-32101.66
-56952.59
$=-81803.53$
-106654.47
$=-131505.42$
$=-156356.36$
-181207.31
-206058.25
-230909.19
-255760.13
-280611.06
-305462.00
-330312.97
-355163.91
-380014.84 \\ $[\mathrm{Pa}]$}

IVR 0.94

Pressure

Contour 1

-7250.72
-32101.66
-56952.59
-81803.53
-106654.47
-131505.42
-156356.36
-181207.31
-206058.25
-230909.19
-255760.13
-280611.06
-305462.00
-330312.97
-355163.91
-380014.84

[Pa]

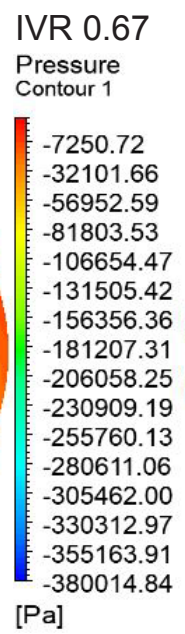

IVR 1.17

Pressure

Contour 1

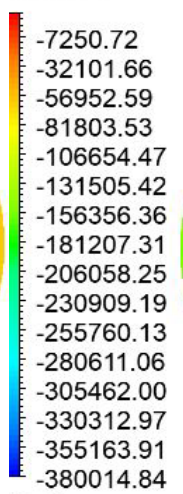

[Pa]

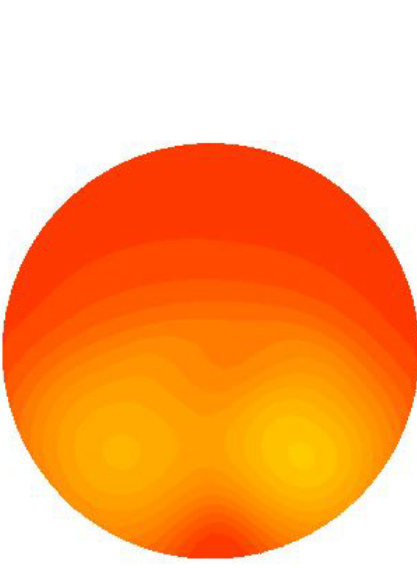

IVR 0.78

Pressure Contour 1

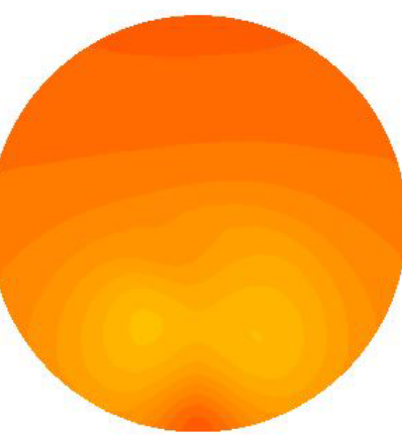

$-380014.84$

[Pa]

IVR 1.64

Pressure

Contour 1

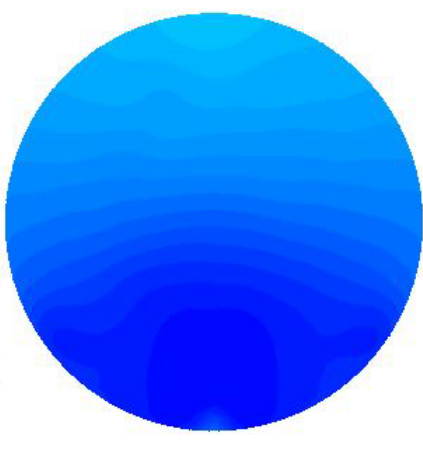

[Pa]

Figure 7: Effect of different IVR values at the inlet passage on the pressure distribution at the outlet section 


\section{Pressure Distribution and Streamline Side View of Pipe}

Fig. 8 shows the contours and streamlines of the entry route with varying IVR values. The results suggest that the flow pattern originating from the inlet was relatively uniform. However, if the IVR condition is too small or too weak, it will produce backflow and flow separation.

\section{Axial-Velocity Distribution Coefficient $\left(V_{u}\right)$ and Weighted Velocity-Averaged Swirl Angle to Inlet Ve- locity Ratio}

This simulation was carried out by finding the coefficient of the axial velocity distribution, which was then varied
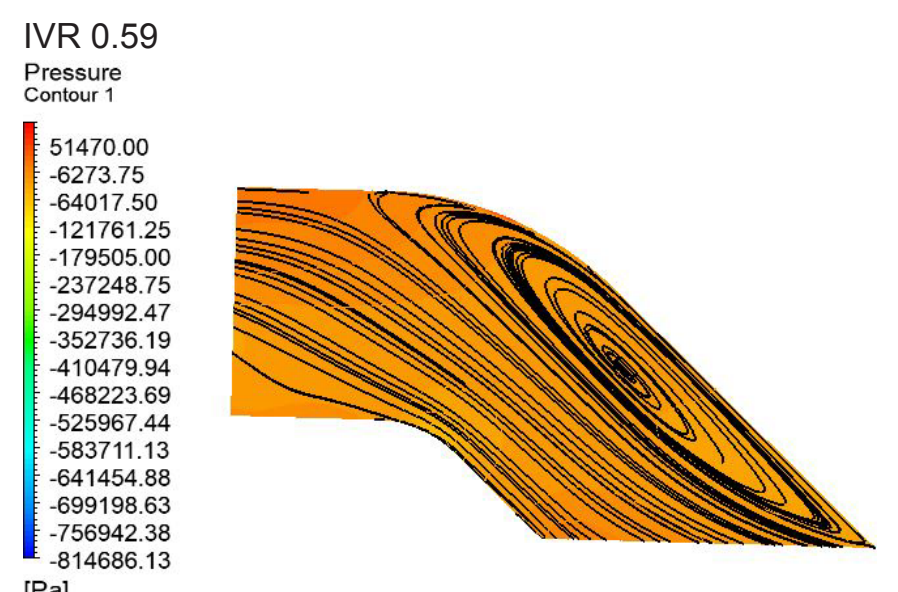

[Pa]

IVR 0.78

Pressure

Contour 1

51470.00

$-6273.75$

$-64017.50$

$-121761.25$

$-179505.00$

$-237248.75$

$-294992.47$

$-352736.19$

$-410479.94$

$-468223.69$

$-525967.44$

$-583711.13$

$-641454.88$

$-699198.63$

$-756942.38$

$-814686.13$

[Pa]

IVR 1.17

Pressure

Contour 1

51470.00

$-6273.75$

$-64017.50$

$-121761.25$

$-179505.00$

$-237248.75$

$-294992.47$

$-352736.19$

$-410479.94$

$-468223.69$

$-525967.44$

$-583711.13$

$-641454.88$

$-699198.63$

$-756942.38$

$\mathrm{Pa}]$
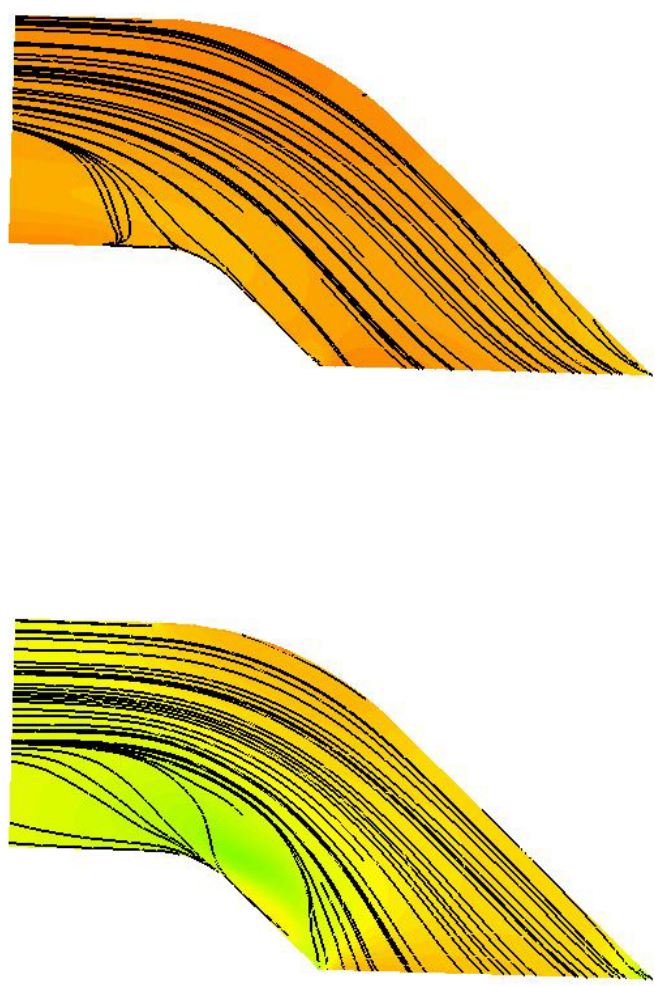

by changing the inlet velocity ratio. In Fig. 9, a graph of the axial-velocity distribution coefficient $\left(V_{u}\right)$ and weighted velocity-averaged swirl angle $(\theta)$ at the outlet section of the entry route are displayed with varying IVR values. These results show that when the IVR value increased, the flow velocity value became uniform at the outlet. When the IVR value was 1.17 , the $V_{u}$ value at the outlet was $98 \%$; the value was $20 \%$ greater than the IVR value of 0.54 . Another simulation was done by finding the axial velocity $\left(U_{a}\right)$ and tangential velocity $\left(U_{t}\right)$, which were varied by changing the IVR. From Fig. 9 , it is known that the IVR value of 0.54 had a good value compared to the others. The resulting graph shows that when the

IVR 0.67

Pressure
Contour 1

51470.00

$-6273.75$

$-64017.50$

$-121761.25$

$-179505.00$

$-237248.75$

$-294992.47$

$-352736.19$

$-410479.94$

$-468223.69$

$-525967.44$

$-583711.13$

$-641454.88$

$-699198.63$

$-756942.38$

[Pa]

IVR 0.94

Pressure

\section{Contour 1}

$-6273.75$

$-64017.50$

$-121761.25$

$-179505.00$

$-237248.75$

$-294992.47$

$-352736.19$

$-410479.94$

$-468223.69$

$-525967.44$

$-583711.13$

$-641454.88$

$-699198.63$

$-756942.38$

$-814686.13$

[Pa]

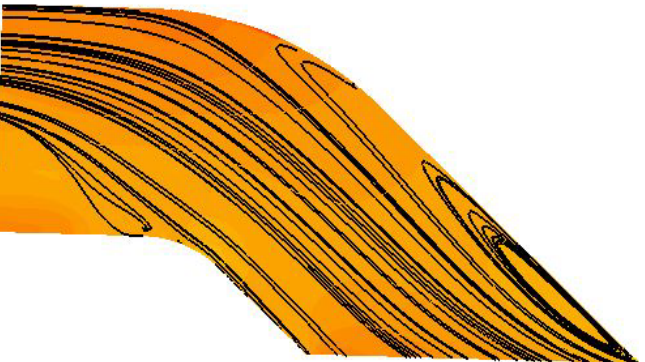

IVR 1.64

Pressure
Contour 1

51470.00

$-6273.75$

$-64017.50$

$-121761.25$

$-179505.00$

$-237248.75$

$-294992.47$

$-352736.19$

$-410479.94$

$-468223.69$

$-525967.44$

$-583711.13$

$-641454.88$

$-699198.63$

$-756942.38$

[Pa]
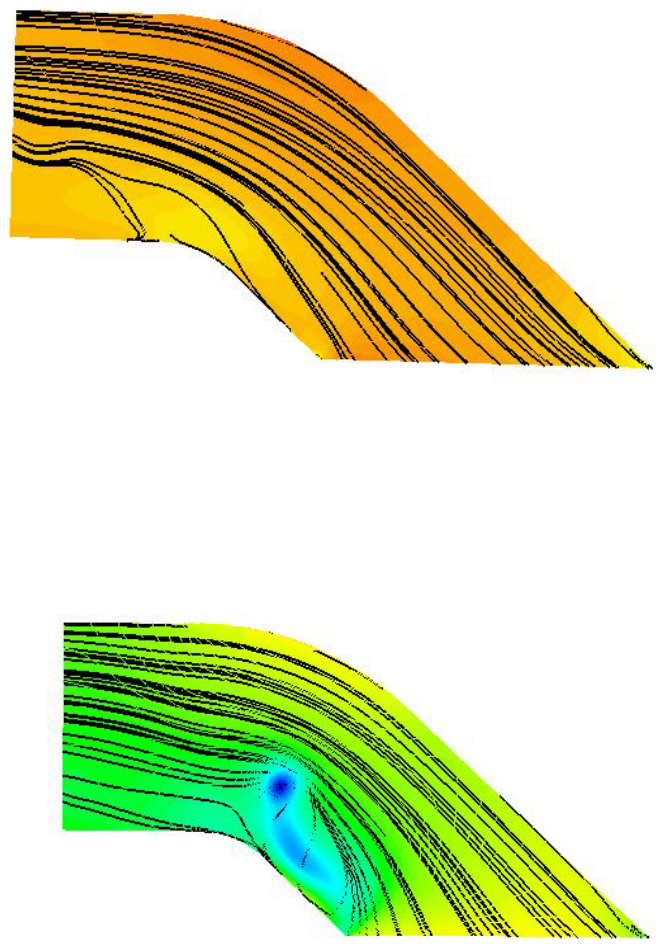

Figure 8: Pressure distribution and streamlined view of the pipe with different IVR values 


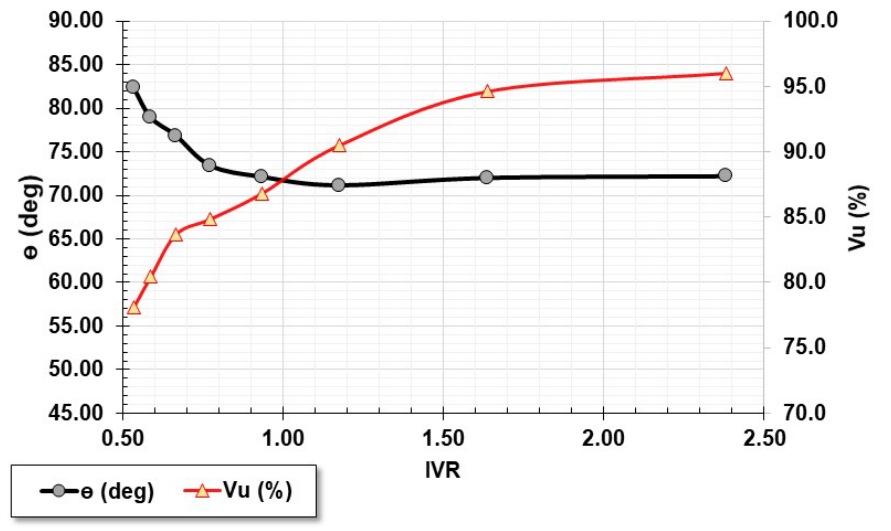

Figure 9: Effect of different IVR values on weighted velocity-averaged swirl angle and axial-velocity distribution coefficient

IVR value increased, the distribution area for high speed also increased and the distribution area for low speed decreased; this result was consistent with previous research that found that as the IVR increased, the uniformity of the flow velocity at the outlet section of an inlet passage increased [35]. When the IVR value was less than 1.18, the weighted velocity-averaged swirl angle at the outlet increased markedly.

\section{Analysis of the optimum value of thrust, IVR, diameter of the waterjet system, and efficiency}

Waterjet performance was sought by determining the optimum diameter that produced the maximum thrust and efficiency; by knowing the optimum diameter, the most efficient IVR could be obtained. The relationship between IVR, thrust, diameter, and efficiency of the model ship waterjet system are shown in Fig. 10. From the simulation results, the water discharge for each variation in the IVR value was obtained. The result can be seen that an IVR value of 2.38 had the highest water discharge, which was $0.05 \mathrm{~m}^{3} / \mathrm{s}$. This value was very large because the value of the inlet velocity ratio is directly proportional to the inlet velocity; when the IVR value is large, it means that the inlet velocity increases. Therefore, it can be concluded that the greatest amount of water passes through the waterjet system with an IVR value of 2.38. By using Equation 3, the thrust value for each IVR variation was obtained. The results show that an IVR value of 2.38 had the greatest thrust value of $50 \mathrm{~N}$. The thrust value increases due to the increasing IVR value. Thus, it can be concluded that the greatest thrust value was at an IVR value of 2.38. By using Equation 5, the efficiency value for each IVR variation was obtained. With an increase in the IVR value, the efficiency value also increases, almost reaching $100 \%$. The result of these calculations was that the greatest efficiency of $98 \%$ was at an IVR value of 2.38.

\section{CONCLUSION}

In this study, a waterjet simulation was carried out with an unmanned marine vehicle; the results were compared with existing experimental data. Based on the simulation results and the calculations above, several conclusions can be drawn. Using variations of the IVR values, the simulation results and a formula calculation to find the thrust value generated the following values: for an IVR value of 0.54 , thrust $=15.99 \mathrm{~N}$; IVR $=0.59$, thrust $=16.07$ $\mathrm{N} ;$ IVR $=0.67$, thrust $=16.25 \mathrm{~N} ;$ IVR $=0.78$, thrust $=21.21$ $\mathrm{N} ;$ IVR $=0.94$, thrust $=26 \mathrm{~N} ;$ IVR $=1.18$, thrust $=30.75$ $\mathrm{N}$; IVR $=1.64$, thrust $=35.40 \mathrm{~N}$; and IVR $=2.38$, thrust $=$ $50 \mathrm{~N}$. The higher the IVR value, the more thrust that was generated. The maximum efficiency of $98 \%$ was when the IVR value was 2.38. A future research suggestion is to conduct more in-depth research on the pressure coefficient $\left(C_{p}\right)$, which functions to determine the value of cavitation that will be generated at the bottom and top of the waterjet inlet.
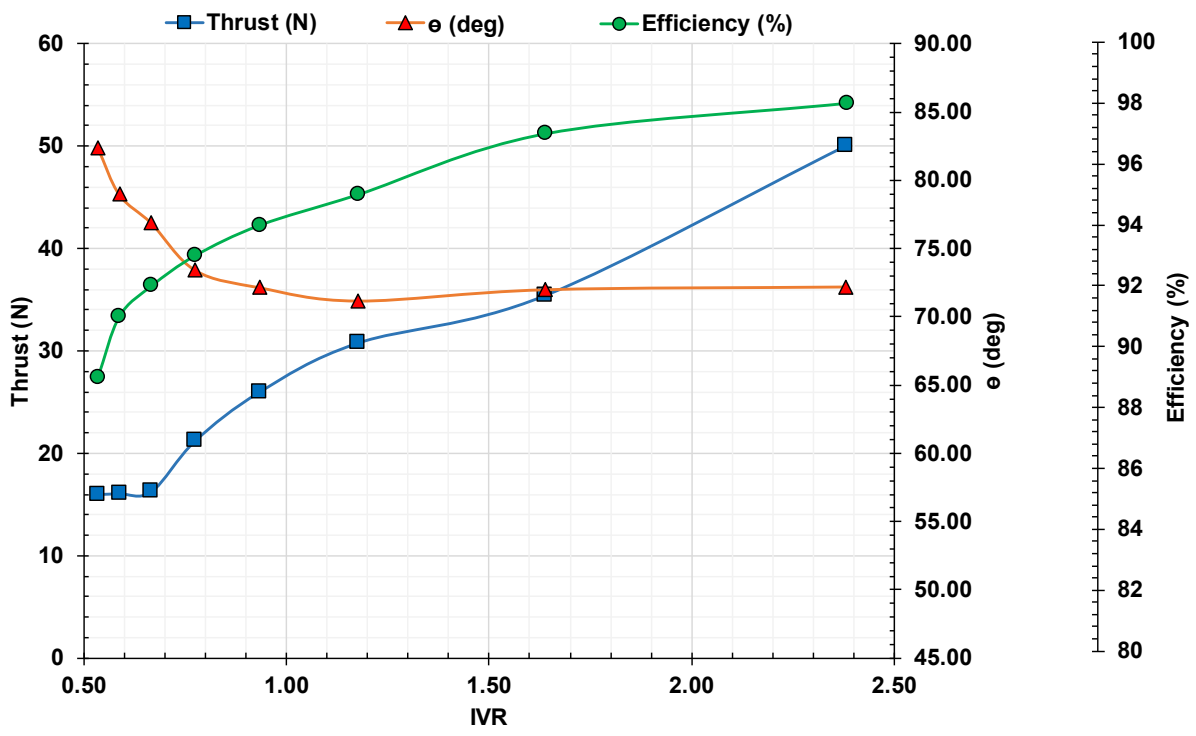

Figure 10: Relationship between IVR, thrust, swirl angle, and efficiency of the waterjet model ship 


\section{ACKNOWLEDGMENTS}

The authors would like to express our gratitude to the Directorate Research and Development Universitas Indonesia (RISBANG-UI) for providing funding from the University of Indonesia through PUTI Q3 NKB-2011/UN2. RST/HKP.05.00/2020.

\section{REFERENCES}

1. Bulten, N. (2008). A Breakthrough in Waterjet Propulsion Systems. Doha International Maritime Defence Exhibition and Conference DIMDEX. https:// doi.org/10.1.1.552.3994

2. Brandau, J. H. (1968). Performance of Waterjet Propulsion Systems- A Review of the State-of-the-Art. Journal of Hydronautics, 2(2), 61-73. https://doi. org $/ 10.2514 / 3.62775$

3. Lee, J.-S., \& Lee, C.-W. (2014). The development of small water-jet propulsion for $150 \mathrm{HP}$ grade inboard type. Journal of the Korean Society of Marine Engineering, 38(3), 246-252. https://doi.org/10.5916/ jkosme.2014.38.3.246

4. Bulten, N. W. H. (2006). Numerical analysis of a waterjet propulsion system. https://doi.org/10.6100/ IR614907

5. Griffith-Jones, G. J. (1994). Investigation of incompressible flow through an intake duct with applications to waterjet propulsion [University of Canterbury]. https://ir.canterbury.ac.nz/handle/10092/7916

6. Roberts, J. (1998). The influence of hull boundary layers on waterjet intake performance [University of Tasmania]. https://eprints.utas.edu.au/21403/

7. Van Esch, B. P. M. (2009). Performance and radial loading of a mixed-flow pump under non-uniform suction flow. Journal of Fluids Engineering, Transactions of the ASME, 131(5), 0511011-0511017. https://doi.org/10.1115/1.3089539

8. Young, Y. L., Savander, B. R., \& Kramer, M. R. (2011). Numerical Investigation of the Impact of SES-Waterjet Interactions and Flow Non-uniformity on Pump Performance. 11th International Conference on Fast Sea Transportation (FAST) , 430-437. https://www. researchgate.net/publication/267844431

9. Cao, P., Wang, Y., Kang, C., Li, G., \& Zhang, X. (2017). Investigation of the role of non-uniform suction flow in the performance of water-jet pump. Ocean Engineering, 140, 258-269. https://doi. org/10.1016/j.oceaneng.2017.05.034

10. Park, W. G., Jang, J. H., Chun, H. H., \& Kim, M. C. (2005). Numerical flow and performance analysis of waterjet propulsion system. Ocean Engineering, 32(14-15), 1740-1761. https://doi.org/10.1016/j. oceaneng.2005.02.004
11. Wang, S., Wang, Y., Jin, S., \& Ding, J. (2013). Effect of Inlet Grid on Duct Flow Performance and Waterjet Propulsion Performance. Journal of Mechanical Engineering, 49(14). http://qikan.cmes.org/zhjc/EN/ abstract/abstract28669.shtml

12. Van Terwisga, T. J. C. (2002). "The Specialist Committee on Validation ofWaterjet Test Procedures" Final Report and Recommendations to the 23rd ITTC. In TUDelft, Faculty of Marine Technology, Ship Hydromechanics Laboratory Report 1333-P, Published in: 23rd International Towing Tank Conference, ITTC'2000, Volume 2, Venice, Italy, September 8-14, 2002 (Vol. 2). https://repository.tudelft.nl/islandora/object/uuid\%3Ab2ae22a4-9f1b-4457-8eaa-cfd07a6f5291

13. Zangeneh, M. (n.d.). The Specialist Committee on Validation of Waterjet Test Procedures. Retrieved March 4, 2021, from https://www.researchgate.net/ publication/237739889

14. Office of Naval Research. (2013). Waterjets Could Propel LCS to Greater Speeds - Office of Naval Research. https://www.onr.navy.mil/en/Media-Center/ Press-Releases/2013/Waterjets-Rolls-Royce-LCSFNC

15. Zürcher, K., Bose, N., Binns, J. R., Thomas, G., \& Davidson, G. (2013). Design and Commissioning Tests for Waterjet Self-Propulsion Testing of a Medium-Speed Catamaran Ferry using a Single Demihull.

16. Kamal, I. M., Zürcher, K., Bose, N., Binns, J., Chai, S., \& Davidson, G. (2015). Powering for Medium Speed Wave-Piercing Catamarans comparing Waterjet and Screw Propeller Performance using Model Testing.

17. Xiros, N. I., Logis, E., Gasparis, E., Tsolakidis, S., \& Kardasis, K. (2009). Theoretical and experimental investigation of unmanned boat electric propulsion system with pmdc motor and waterjet. Journal of Marine Engineering and Technology, 8(2), 27-43. https://doi.org/10.1080/20464177.2009.11020221

18. Coop, H. G. (1995). Investigation of hull-waterjet interaction effects [University of Canterbury]. https:// ir.canterbury.ac.nz/handle/10092/8098

19. Guo, J., Chen, Z., \& Dai, Y. (2020). Numerical study on self-propulsion of a waterjet propelled trimaran. Ocean Engineering, 195, 106655. https://doi. org/10.1016/j.oceaneng.2019.106655

20. Zhang, L., Zhang, J. N., Shang, Y. C., Dong, G. X., \& Chen, W. M. (2020). A Practical approach to the assessment of waterjet propulsion performance: The case of a waterjet-propelled trimaran. Polish Maritime Research, 26(4), 27-38. https://doi. org/10.2478/pomr-2019-0063 
21. Qiu, J.-T., Yang, C.-J., Dong, X.-Q., Wang, Z.-L., Li, W., \& Noblesse, F. (2018). Numerical Simulation and Uncertainty Analysis of an Axial-Flow Waterjet Pump. Journal of Marine Science and Engineering, 6(2), 71. https://doi.org/10.3390/jmse6020071

22. Jiao, Cheng, Xu, \& Wang. (2019). Numerical Analysis of Two-Phase Flow in the Cavitation Process of a Waterjet Propulsion Pump System. Processes, 7(10), 690. https://doi.org/10.3390/pr7100690

23. Han, W., Shang, T., Su, M., Gong, C., Li, R., \& Meng, B. (2019). Direct Sailing Variable Acceleration Dynamics Characteristics of Water-Jet Propulsion with a Screw Mixed-Flow Pump. Applied Sciences, 9(19), 4194. https://doi.org/10.3390/app9194194

24. Gong, J., Guo, C. yu, Wang, C., Wu, T. cheng, \& Song, K. wei. (2019). Analysis of waterjet-hull interaction and its impact on the propulsion performance of a four-waterjet-propelled ship. Ocean Engineering, 180, 211-222. https://doi.org/10.1016/j. oceaneng.2019.04.002

25. Eslamdoost, A., Larsson, L., \& Bensow, R. (2018). Analysis of the thrust deduction in waterjet propulsion - The Froude number dependence. Ocean Engineering, 152, 100-112. https://doi.org/10.1016/j. oceaneng.2018.01.037

26. Huang, R., Dai, Y., Luo, X., Wang, Y., \& Huang, C. (2019). Multi-objective optimization of the flush-type intake duct for a waterjet propulsion system. Ocean Engineering, 187, 106172. https://doi.org/10.1016/j. oceaneng.2019.106172

27. Budiyanto, M. A., Novri, J., Alhamid, M. I., \& Ardiyansyah. (2019). Analysis of convergent and divergent-convergent nozzle of waterjet propulsion by CFD simulation. AIP Conference Proceedings, 2062(1), 020066. https://doi.org/10.1063/1.5086613

28. Zhang, Z., Cao, S., Shi, W., Luo, X., Wang, H., Deng, J., \& Zhu, Y. (2018). High pressure waterjet propulsion with thrust vector control system applied on underwater vehicles. Ocean Engineering, 156, 456-467. https://doi.org/10.1016/j.oceaneng.2018.03.009

29. Gong, J., Guo, C. Y., Wu, T. C., \& Song, K. W. (2018). Numerical study on the unsteady hydrodynamic performance of a waterjet impeller. Journal of Coastal Research, 34(1), 151-163. https://doi.org/10.2112/ JCOASTRES-D-16-00210.1
30. Budiyanto, M. A., Syahrudin, M. F., \& Murdianto, M. A. (2020). Investigation of the effectiveness of a stern foil on a patrol boat by experiment and simulation. Cogent Engineering, 7(1), 1716925. https://doi. org/10.1080/23311916.2020.1716925

31. Budiyanto, M. A., Murdianto, M. A., \& Syahrudin, M. F. (2020). Study on the resistance reduction on highspeed vessel by application of stern foil using cfd simulation. CFD Letters, 12(4), 35-42. https://doi. org/10.37934/cfdl.12.4.3542

32. Wang, C., He, X., Cheng, L., Luo, C., Xu, J., Chen, K., \& Jiao, W. (2019). Numerical simulation on hydraulic characteristics of nozzle in waterjet propulsion system. Processes, 7(12), 915. https://doi. org/10.3390/PR7120915

33. Xia, C. Z., Cheng, L., Shang, Y. N., Zhou, J. R., Yang, F., \& Jin, Y. (2016). Numerical simulation on the cavitation of waterjet propulsion pump. IOP Conference Series: Materials Science and Engineering, 129(1). https://doi.org/10.1088/1757-899X/129/1/012011

34. Xia, C., Cheng, L., Luo, C., Jiao, W., \& Zhang, D. (2018). Hydraulic characteristics and measurement of rotating stall suppression in a waterjet propulsion system. Transactions of Famena, 42(4), 85-100. https://doi.org/10.21278/TOF.42408

35. Jiao, W., Cheng, L., Zhang, D., Zhang, B., Su, Y., \& Wang, C. (2019). Optimal Design of Inlet Passage for Waterjet Propulsion System Based on Flow and Geometric Parameters. Advances in Materials Science and Engineering, 2019. https://doi. org/10.1155/2019/2320981

36. Ansys. (2020). Ansys Fluent: Fluid Simulation Software. (C) ANSYS, Inc. All rights reserved. https://www. ansys.com/products/fluids/ansys-fluent

37. Ansys Fluent 12.0 Theory Guide - 1.2 Continuity and Momentum Equations. (n.d.). Retrieved March 4, 2021, from https://www.afs.enea.it/project/neptunius/docs/fluent/html/th/node11.htm

38. ITTC. (n.d.). ITTC-Recommended Procedures and Guidelines ITTC Quality System Manual Recommended Procedures and Guidelines. 